Europe's Journal of Psychology, 7(3), pp. 550-564

www.ejop.org

\title{
Health Psychology's role in sexual health care
}

Jude Hancock

SASH team, Applied Research Centre in Health and Lifestyle Interventions, Coventry University, UK

Susan Lees

Department of Nursing, Midwifery and Health Care, Coventry University, UK

Katherine E. Brown

SASH team, Applied Research Centre in Health and Lifestyle Interventions, Coventry University, UK

\begin{abstract}
This article provides an overview of the current and potential role of health psychology in sexual health care. Research, which applies various behaviour change techniques, is reviewed alongside one of the most extensively used theories, the Theory of Planned Behaviour (see Conner and Sparks 2009). This paper aims to link theory to practice giving the reader an indication of the range of work that health psychologists are involved in, and how this could be applied to sexual healthcare practice which supports positive behaviour change.
\end{abstract}

Keywords: Health psychology, theory of planned behaviour, intervention.

Sexual health care is an umbrella term encompassing topics such as family planning, sub-fertility, sexually acquired infections (SAI), female genital mutilation and sex and relationships education (World Health Organisation, 2010). This paper will provide a definition of a health psychologist and evaluate their role in the provision of sexual health care by considering the issues related to informing and supporting behaviour change in a variety of different settings, including reference to appropriate and relevant research. 
The ways in which sexual health services are provided, and the health care professionals who deliver these services differ considerably by country and region (Bellamy, 2002; Department of Health, 2010a; Faculty of Family Planning and Reproductive Health Care, 2006; Marie Stopes International, 2009; Moya, 2002). Many countries are seeing a rise in the number of people living with HIV (World Health Organisation, 2009), and being diagnosed with SAI as a result of risky behaviour (Misovich, Fisher \& Fisher, 1992). Behaviour change is one focus of health psychology; which may be well placed to tackle these increasing figures. This paper will consider different techniques that health psychologists have applied to change behaviour such as, motivational interviewing and supporting formation of implementation intentions.

The discipline of psychology emerged in the 1800s and is defined by the British Psychological Society (BPS) as "the scientific study of people, the mind and behaviour" (Bunn, 2008; BPS, 2010a). Health psychology emerged as a profession to address the failure of the medical model to acknowledge the psycho-social influences on individual's health (Matarazzo, 1982). Health Psychologists "scientifically study the psychological process of health, illness and health care" which may be used to promote healthy lifestyles and help individuals maintain their health or manage existing conditions such as diabetes (BPS, 2010b). Health psychologists may work directly with patients, families and carers as well as directing initiatives relating to health policy, promotion, education and research (DHP, 2009). Health psychologists are bound by professional guidelines outlined by the Health Professions Council (2008) and the British Psychological Society (1993) both underpinned by the philosophy that care should be provided with impartiality and respect for the person being treated. There are also academic health psychologists who do not work directly with patients but are based in academic institutions; they often provide consultancy advice on health care service provision based on rigorous scientific research (DHP, 2009).

In 2002, the faculty of HIV and sexual health, a subgroup of the BPS Division of Clinical Psychology, carried out a survey of clinical psychologists working in sexual health settings (Shaw \& Cutler, 2002). They found Clinical Psychologists worked in a range of settings, including, genitourinary medicine clinics (GUM), HIV inpatients and outpatients, directly in the community and clinics for psychosexual issues. When asked how they worked with clients, techniques such as cognitive behavioural therapy (CBT), counselling, health behaviour, solution focussed therapy and psychodynamic methods were cited. The focus of clinical psychology is to deal with mental and physical health problems in order to promote psychological well-being whereas in health psychology the focus is to promote change in the way people 
think about their health in order to promote good health and prevent illness (BPS, 2010b). Behaviour change techniques used by health psychologists include goal setting, action planning and exploration of barriers and facilitators of change, all used collaboratively with the patient (Michie et al. 2008).

In terms of reproductive health care, academic health psychologists, have been influential in developing interventions to promote safer sex. Nurses have benefited from health psychology in terms of understanding the psychological mechanisms underpinning individuals' behavioural choices, in order to apply these to sexual health assessment (Browes, 2006). Interventions to change behaviour have been found to be most effective when they are grounded in theory and are preceded by elicitation studies in the population to be targeted (Fisher \& Fisher, 1992). Many interventions promoting safer sexual practices have been based on the theory of planned behaviour (TPB; Ajzen, 1991). The theory states that an individual's intentions to perform a given behaviour (e.g. have safer sex) are influenced by three variables: 1. attitude toward the behaviour, 2. subjective norm and, 3. perceived behavioural control, as illustrated in figure 1 (Ajzen, 2006).

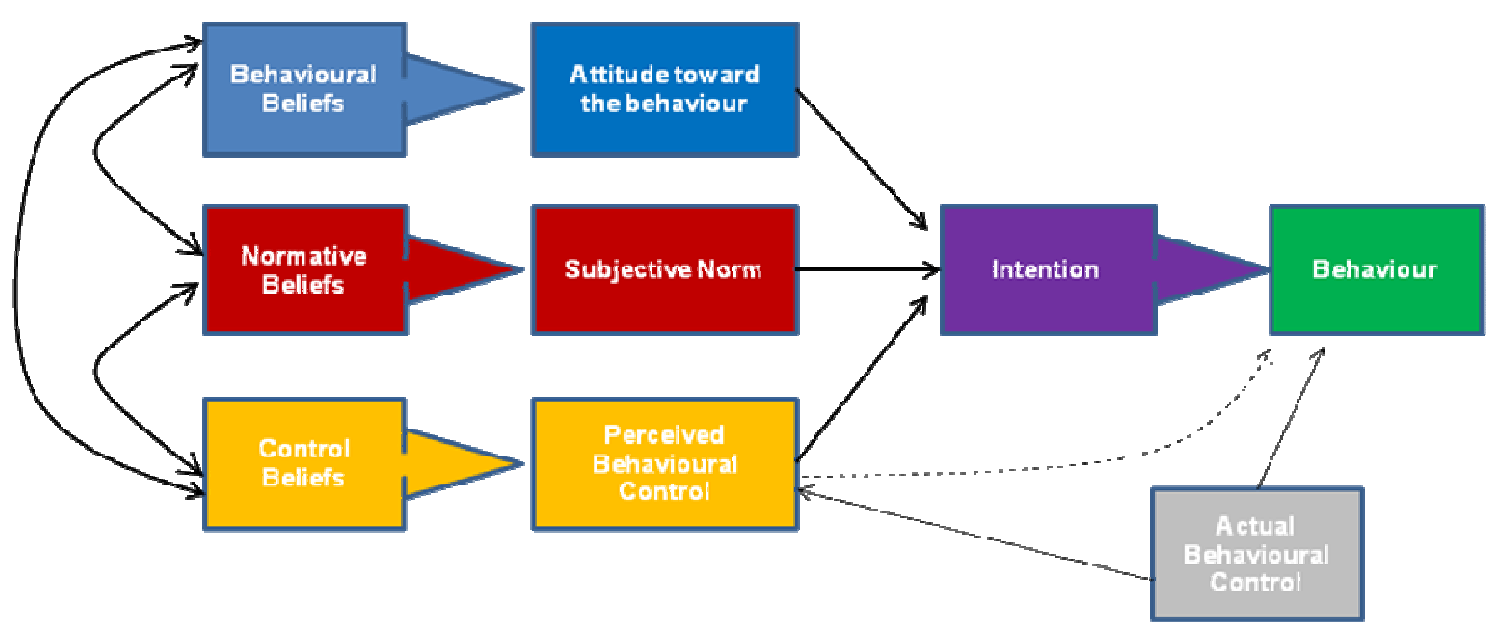

Figure 1: Diagram of the Theory of Planned Behaviour

Figure one shows that an individual's underlying beliefs influence intention and subsequent behaviour. The TPB variables are derived from multiplicative composites in that an individual's beliefs are a combination of belief multiplied by outcome. For example, an individual's attitude is determined by the perceived likelihood of an outcome occurring multiplied by an evaluation of that outcome (Conner \& Norman 2009, p. 176). An attitude may be positive or negative toward the behaviour. Subjective norms (SN) are the perceived social pressures from important others to 
perform behaviour, which like attitudes are formed from individuals' salient normative beliefs. SN is measured by the perceived social pressure from salient referents multiplied by the motivation to comply with their requests (Conner and Norman 2009, p. 176). Perceived behavioural control (PBC) comprises of an individual's salient control beliefs, how much control they feel they have over performing the behaviour given both internal and external factors (Ajzen, 1991). PBC is measured by the perceived belief strength from salient beliefs multiplied by the control belief power to perform the behaviour (Ajzen, 2006). The theory recognises that variables external to the model such as demographics, personality traits and environmental factors will influence beliefs (Conner \& Norman 2009, p. 176).

In terms of sexual health care interventions the TPB recognises that the importance of the attitude, SN or PBC variables will vary in different populations (Fishbein, 2000). An example of this would be in relation to adolescent behaviour, where age has been found to influence salient beliefs and be particularly influential on attitudes and SN variables (Sheeran et al., 1990). Safer sex using condoms has also been found to vary in relation to whether an individual is having intercourse with their main partner or a casual partner. Montano, Kasprzyk, von Haeften, and Fishbein (2001) demonstrated that $\mathrm{SN}$ is influential for condom use with a main partner for example, respecting and complying with partners' wishes, but with a casual partner attitude is more influential (e.g. knowing that using a condom will reduce the chance of contracting a sexually acquired infection). Health psychologists need to understand these underlying beliefs in order to design behaviour change interventions.

Bryan, Aiken and West (1996) developed a theory-based intervention that aimed to increase condom use in young women to prevent SAI. They argued that many interventions are targeted at HIV prevention and yet other SAI are more prevalent in the general population, which is certainly the case in the United Kingdom (Office for National Statistics, 2006; Health Protection Agency, 2009, Avert, 2010). They recognised that attitudes toward condoms were important, but other variables such as the perceived susceptibility to and severity of contracting an SAI as well as the perceived benefits of condom use were worth targeting. Furthermore, during a sexual encounter an individual needs to be assertive about their intent to use a condom. This links to the PBC variable in the TPB as well as Bandura's (1977) concept of self-efficacy. Self-efficacy is defined as "...the conviction that one can successfully execute the behaviour required to produce the outcomes" (Bandura 1977, p. 192). In 1994 Bandura noted that mastering experiences (such as using condoms) could result in the achievement of a 'strong sense of self-efficacy'. To target these variables Bryan et al. (1996) used a combination of videotaped segments, lecture presentations alongside audience participation in one 45-minute 
session. Six months later, self-reported condom use had increased along with the perceived benefits of condom use, control over the sexual encounter, perceived self-efficacy for condom use, and intentions to use condoms. This intervention clearly demonstrates that using a theoretical framework not only aids intervention planning but helps to sustain changes in behaviour over a period of time.

Weinstein (1980) developed the concept of 'optimistic bias' to explain how some individuals have 'unrealistic optimism' about future events, for example, belief in the myth that 'you cannot get pregnant the first time you do it'. Health psychologists often use motivational interviewing (MI) to help change behaviour and reduce unrealistic optimism (Rollnick \& Miller, 1995). Motivational interviewing is a client-led technique, which can produce behaviour change by helping clients explore and reduce ambivalence toward behaviour. $\mathrm{MI}$ is closely related to the transtheoretical model of change (TTM) which states that individual's move through five stages of intentional behaviour change; precontemplation (not thinking about changing their behaviour), contemplation (thinking about behaviour change), preparation (ready to attempt behaviour change), action (making an active effort to change behaviour) and maintenance (sustaining the desired behaviour change) (Prochaska \& DiClemente, 1984; Prochaska, DiClemente \& Norcross (1992). The TTM assumes that "individuals who are in different stages of change have different psychosocial characteristics from individuals who are in another stage of change" (Sarafino, 1998, p. 178). An example would be an individual in the precontemplation stage practicing a risky behaviour, such as unsafe sex, who is likely to have less belief in their abilities to perform safer sex (i.e. low self-efficacy) and see more barriers than benefits for practicing safer sex than an individual in the action stage that often practices safer sex. MI can be used to encourage individuals to move from an earlier to later stage of behaviour change with an aim to ultimately move and stay in the maintenance stage.

Although MI was originally developed for problem drinkers, it can be applied successfully to a plethora of behaviours (Michie et al. 2008). Motivational interviewing may be used with women who are regular users of emergency contraception, to motivate them to change to being regular and consistent contraception users (Peterson et al. 2004). Using an Ml-based approach this would be achieved in three stages. The first stage involves listening to a woman's story about why she is currently not using contraception. Secondly, the clinician imparts some knowledge about the benefits of regular and consistent contraceptive use (e.g. intrauterine systems effectively prevent unwanted pregnancy and may help with heavy menstruation or, using condoms will prevent unwanted pregnancies and SAl if the woman does not have a main partner) (Faculty of Sexual and 
Reproductive Healthcare, 2007a; Faculty of Sexual and Reproductive Healthcare, 2007b). The third and final stage is the exploration of potential benefits from undertaking the behaviour where the clinician reflects the words of the client back to them so they can hear the commitment to change they are making. Scaling questions may be used to elicit the importance of the change and the client's confidence in undertaking the change. MI techniques have also been successfully applied in HIV risk-reduction with specific 'at-risk' populations such as gay men (Harding, Dockrell, Dockrell \& Corrigan, 2001).

Research within sexual health services has demonstrated that using a different approach, that of planning techniques can also change behaviour by reducing consultations for pregnancy testing and emergency contraception in teenage women (Martin, Sheeran, Slade, Wright, and Dibble, 2009). Implementation intentions are a brief planning technique used to change an individual's intention into action. A meta-analysis of 94 studies using this technique showed it to have a medium-tolarge effect size ( $d=.65)$ (Gollwitzer \& Sheeran, 2006). To form an implementation intention a person develops an if-then plan, for example with using a contraceptive pill effectively, a woman may state, "If I am getting dressed, then I will take my pill". Health Psychologists are well positioned to teach other health care professionals working in reproductive healthcare, such as sexual health clinics, how to use this simple yet effective technique with clients. In the study by Martin et al. (2009) the formation of implementation intentions reduced consultations for pregnancy testing and emergency contraception. Only $38 \%$ in the experimental group returned for pregnancy testing or emergency contraception compared to $55 \%$ in the control group. This study was longitudinal with a 9-month follow-up. From the eight-hundred and twenty-six women aged 19 years and under attending the clinic during the study period, two hundred and sixty-one women were randomised to either the implementation or control condition, surprisingly during the 9-months only sixty-one women were lost to follow-up. This study demonstrates the power of implementation intentions in the long-term in a good size sample within a clinical setting. Although the authors noted that the positive findings were from one clinic and furthermore, contraceptive services delivered elsewhere (e.g. general practice or pharmacies) were not monitored, so women may have accessed these services for emergency contraception.

The recent past has seen a growing number of websites dedicated to assisting people living with long-term conditions. A review by Phoenix and Coulson (2010) highlighted that the use of the Internet for people living with HIV /AIDS had positive psychosocial outcomes such as adherence to antiretroviral treatments, increased knowledge about HIV, active and information-seeking coping and better emotional 
health. The use of HIV-specific online support systems gave people online support and allowed interaction between others living with HIV. The fact that the Internet can often help people living with a condition but who are geographically isolated, is a major benefit of using this technology (Pequegnat et al. 2007). Phoenix and Coulson (2010) do not promote the Internet as a replacement for face-to-face consultations, but as an adjunct to traditional services. Websites such as NHS Choices are an excellent resource for information about sexual health (NHS Choices, 2010), but websites alone do not necessarily lead to a change in behaviour, or sustain positive psychological outcomes such as HIV-specific sites.

The foundation of health psychology training is research, which is crucial in service planning. Health psychologists are well trained to undertake research on service delivery and client preferences utilising, for example, qualitative methods such as interviewing (Grbich, 1999). Qualitative research can be used to answer health questions such as, why did you decide to use a walk in centre to obtain emergency contraception rather than your GP or local pharmacy? These questions are difficult to answer using a traditional scientific method (Chamberlain, 2004). Furthermore, qualitative research can allow patients to tell their story, which may be used tailor sexual health services for specific populations (Nzioka, 2000). A disadvantage of qualitative research is that it does not allow for findings to be generalised outside of the sampled population, however, this is widely acknowledged as a feature of quantitative research (Polit \& Beck, 2011). The generalisability of findings from quantitative research depends on the study sample, many safer sex interventions are developed in students samples that are not necessarily representative of the general population (Armitage \& Talibudeen, 2010; Sheeran \& Taylor, 2006). A mixed methods approach, where both qualitative and quantitative data are collected, is recommended as the most appropriate way to develop TPB theory-based interventions (Sutton, 2002). Triangulating findings from use of mixed methods allows clarification of theoretical assumptions (Östlund, Kidd, Wengström, and RowaDewar, 2011 ), yet in practice this is rarely achieved, often due funding issues (Fisher \& Fisher, 1992).

Using a qualitative approach Chouliara, Karatzias, Day, and Goulbourne (2009) interviewed 12 female university students and identified six themes about chlamydia: 1. facts versus risk misjudgements, 2 . social stigma and taboos, 3. assertiveness versus fear of conflict, 4. respect versus being patronised, 5. accessibility and discretion, and 6. targeting young people. The findings concluded that women wanted effective sexual health education and were concerned with the shame, embarrassment and social stigma associated with chlamydia testing and diagnosis. These findings highlight the need for sexual health services that are accessible and 
discrete. The authors state "anonymity, confidentiality, open access and a relaxed and friendly atmosphere was thought to be at the core of providing effective and user-friendly services" (Chouliara et al. 2009, p.22). Furthermore, "feeling patronised, deprived of enough choice, rushed and pressured for time were identified as factors that can undermine the quality of services provided to such women and making their experiences of using the services more distressing" (Chouliara et al. 2009, p. 22). This research highlights the service that health psychologists can provide in helping commissioners and frontline staff in delivering effective sexual health care. Knowing what clients think about the services they access enables commissioners and frontline staff to change practice in a positive way.

In November 2010, the government published 'Healthy Lives, Healthy People: Our strategy for public health in England' (Department of Health, 2010b). The publication recognises that a new approach to public health is needed that "empowers people to make healthy choices" and that health is a lifelong challenge. In terms of reproductive healthcare this is particularly challenging as sexual health is often viewed as a topic for those who are able to reproduce (Nusbaum \& Rosefeld, 2004). Clinicians report initiating sexual health discussion with clients as difficult, especially during routine screening, particularly with older people (Nusbaum and Rosefeld, 2004). Yet, the Department of Health (2010) document reiterates that SAI figures are rising, which is also supported by Office for National Statistics data (ONS, 2006). Health psychologists are well positioned to help change risk-taking sexual behaviour that leads to a spread of SAI regardless of an individual's sexual orientation, gender, ethnicity, age, religious beliefs, or disabilities, all factors found to influence an individual's salient belief that ultimately underlie intention to perform (or not) a riskybehaviour such as unprotected sexual intercourse with multiple partners (Sheeran, Abraham, Abrams, and Spears, 1990).

To date, clinical psychologists dominate the clinical work undertaken in reproductive healthcare but health psychologists have contributed greatly to intervention design, development and evaluation, as well as teaching and training other health care professionals in behaviour change techniques (Newson \& Forshaw, 2009). This paper has discussed reproductive health care in terms of the reduction of risky behaviours that lead to negative outcomes, unwanted pregnancy and SAl; in conjunction with different techniques that may be used to change risky behaviours. Behaviour change may also be about promoting behaviours that lead to a positive outcome, for example, men and women altering unhealthy lifestyles that can assist in conception where subfertility issues have been identified as being present (Lees, 2010). Health psychology is still a new profession compared to others (e.g. nursing) but has already contributed considerably to the field of reproductive healthcare in 
terms of for example, understanding how teenagers view emergency contraception (Bayley, Brown \& Wallace, 2009), developing brief interventions that can positively change behaviour (Martin et al. 2009) and using modern technology to assist individuals living with long-term conditions such as HIV (Phoenix \& Coulson, 2010). Increasing the involvement of health psychologists in sexual health service delivery would compliment other professional roles and help to tackle the limited psychological therapeutic services currently available (Taylor and Lavender, 2007). Future sexual health research, particularly in terms of safer sex, should focus on the 'general population' who have largely been ignored (Bowleg, 2011). This needs to include older people due to the rise in SAI diagnosis in this group (Bodley-Tickell et al. 2008).

\section{References}

Ajzen, I. (2006). TPB Diagram. Retrieved December, 20, 2010, from www.people.umass.edu/aizen/tpb.diag.html

Ajzen, I. (2006). Constructing a TpB Questionnaire: Conceptual and Methodological Considerations. Retrieved February, 19, 2010 from www.people.umass.edu/aizen/pdf/tpb.measurement.pdf

Ajzen, I. (1991). The Theory of Planned Behavior. Organizational Behavior and Human Decision Process, 50, 179-211.

Armitage, C.J. \& Talibudeen, L. (2010). Test of a brief theory of planned behaviourbased intervention to promote adolescent safe sex intentions. British Journal of Psychology, 101, 155-172.

Avert (2010). Sexually Transmitted Diseases in the UK. Retrieved July, 1, 2010, from www.avert.org/std-statistics-uk.htm

Bandura, A. (1994). Self-Efficacy. In Ramachaudran, V. S. (ed.) Encyclopaedia of Human Behavior, $4^{\text {th }}$ edition, (pp. 71-81). New York: Academic Press.

Bandura, A. (1977). Self-Efficacy: Toward a Unifying Theory of Behavioural Change. Psychological Review, 84, 191-215.

Bayley, J., Brown, K., \& Wallace, L. (2009). Teenagers and Emergency Contraception in the UK: A Focus Group Study of Salient Beliefs using Concepts from the Theory of Planned 
Behaviour. The European Journal of Contraception and Reproductive Health Care, 14 (3), 196-206.

Bellamy, R. (2002). AIDS in Africa. Retrieved February, 21, 201 1, from http://www.sexualhealthmatters.com/v6iss2/article3.html

Bodley-Tickell, A.T., Olowokure, B., Bhaduri, S., White, D.J., Ward, D., Ross, J.D.C., Smith, G., Duggal, H.V. \& Goold, P. (2008). Trends in sexually transmitted infections (other than HIV) in older people: analysis of data from an enhanced surveillance system. Sexually Transmitted Infections, 84, 312-317.

Bowleg, L. (2011). The "forgotten": Where are the heterosexually active men in HIV prevention theory, research and interventions? Psychology and AIDS Exchange, 3 (36), 1-6.

British Psychological Society (1993). Code of Ethics and Conduct: Guidance Published by the Ethics Committee of the British Psychological Society. Leicester: The British Psychological Society.

British Psychological Society (2010a). Types of Psychologist. Retrieved December, 20, 2010, from http://www.bps.org.uk/careers/what-do-psychologistsdo/areas/areas_home.cfm

British Psychological Society (2010b). The Division of Health Psychology. Retrieved August, 25, 2010 from www.health-psychology.org.uk

Browes, S. (2006). Health Psychology and Sexual Health Assessment. Nursing Standard, 21 (5), 35-39.

Bryan, A. D., Aiken, L. S., \& West, S. G. (1996). Increasing Condom use: Evaluation of a Theory-Based Intervention to Prevent Sexually Transmitted Diseases in Young Women. Health Psychology, 15 (5), 371-382.

Bunn, G. (2008). A Chronology of Psychology in Britain. London: BPS.

Chamberlain, K. (2004). Qualitative Research, Reflexivity and Context. In Murray, M. (ed.) Critical Health Psychology (pp.121-136). Basingstoke: Palgrave Macmillan.

Chouliara, Z., Karatzias, T., Day, L., \& Goulbourne, A. (2009).'Views and Experiences of Young Women about Chlamydia in Scotland: Knowledge, Condom use and Access to Health Services. Health Psychology Update, 18 (2), 14-24. 
Conner, M., \& Sparks, P. (2009). Theory of Planned Behaviour and Health Behaviour. In Conner, M., and Norman, P. (eds.), Predicting Health Behaviour, $2^{\text {nd }}$ edition. (pp. 170222). Maidenhead, England: Open University Press.

Department of Health (2010a). Equality Impact Assessment for National Sexual Health Policy. London: The Stationary Office.

Department of Health (2010b). Healthy Lives, Healthy People: Our Strategy for Public Health in England. London: The Stationary Office.

Division of Health Psychology (2009). What is Health Psychology? Leicester: Division of Health Psychology, British Psychological Society.

Faculty of Family Planning and Reproductive Health Care (2006). Service standards for sexual health services. London: Faculty of Family Planning and Reproductive Health Care.

Faculty of Sexual and Reproductive Healthcare (2007a). Intrauterine Contraception. London: Faculty of Sexual and Reproductive Healthcare.

Faculty of Sexual and Reproductive Healthcare (2007b). Male and Female Condoms. London: Faculty of Sexual and Reproductive Healthcare.

Fishbein, M. (2000). The Role of Theory in HIV Prevention. AIDS Care, 12 (3), 273-278.

Fisher, J. D., \& Fisher, W. A. (1992). Changing AIDS-Risk Behavior. Psychological Bulletin, 111 (3), 455-474.

Gollwitzer, P. M., and Sheeran, P. (2006). Implementation Intentions and Goal Achievement: A Meta-Analysis of Effects and Processes. In Zanna, M. P. (ed.), Advances in Experimental Social Psychology, Vol 38. San Diego, CA US: Elsevier Academic Press, 69119.

Grbich, C. (1999). Qualitative Research in Health: An Introduction. Thousand Oaks, CA: Sage Publications Ltd.

Harding, R., Dockrell, M.J.D., Dockrell, J. \& Corrigan, N. (2001). Motivational Interviewing for HIV risk-reduction among gay men in commercial and public settings, AIDS Care, 13 (4), 493-501. 
Health Professions Council (2008). Standards of Conduct, Performance and Ethics. London: Health Professions Council.

Health Protection Agency (2009). HIV and Sexually Transmitted Infections. Retrieved March, 25, 2010 from www.hpa.org.uk/HPA/Publications/InfectiousDiseases/HIVAndSTIs

Lees, S. (2010). Subfertility [Lecture] Module 326CPD, 8 December 2010. Lecture edn. Coventry: Coventry University.

Marie Stopes International (2009). Global Impact Report. London: Marie Stopes International.

Martin, J., Sheeran, P., Slade, P., Wright, A., \& Dibble, T. (2009). Implementation Intention Formation Reduces Consultations for Emergency Contraception and Pregnancy Testing among Teenage Women. Health Psychology, 28 (6), 762-769.

Matarazzo, J. D. (1982). Behavioral Health's Challenge to Academic, Scientific, and Professional Psychology. American Psychologist, 37 (1), 1-14.

Michie, S., Rumsey, N., Fussell, A., Hardeman, W., Johnston, M., Newman, S., \& Yardley, L. (2008). Improving Health: Changing Behaviour - NHS Health Trainers Handbook. London: Department of Health.

Misovich, S.J, Fisher, J.D., \& Fisher, W.A. (1992). The perceived AIDS-preventative utility of knowing one's partner well: A public health dictum and individuals' risky sexual behavior. Canadian Journal of Human Sexuality, 5 (2), 83-90.

Montano, D., Kasprzyk, D., von Haeften, I., \& Fishbein, M. (2001). Toward an Understanding of Condom use Behaviours: A Theoretical and Methodological Overview of Project SAFER. Psychology, Health \& Medicine, 6 (2), 139-150.

Moya, C. (2002). Creating youth-friendly sexual health services in Sub-Saharan Africa. Washington, DC: Advocates for Youth.

Newson, L. \& Forshaw, M. (2009). Health Psychologists in the NHS. Health Psychology Update, 18 (2), 30-33.

NHS Choices (2010). Sexual Health. Retrieved February, 7, 2010, from

www.nhs.uk/Livewell/Sexualhealthtopics/Pages/Sexual-health-hub.aspx 
Nusbaum, M. \& Rosenfeld, J. A. (2004). Sexual Health Across the Lifecycle. Cambridge: Cambridge University Press.

Nzioka, C. (2000). The social meaning of death from HIV/AIDS: An African interpretative view. Culture, Health and Sexuality, 2 (1), 1-14.

Office for National Statistics (2006). Sexual Health: HIV and Chlamydia Diagnoses Increasing. Retrieved June, 30, 2010, from

www.statistics.gov.uk/cci/nugget_print.asp? ID=1330

Östlund, U., Kidd, L., Wengström, Y. and Rowa-Dewar, N. (2011). Combining qualitative and quantitative research within mixed methods research design: $A$ methodological review. International Journal of Nursing Studies, 48 (3), 369-383.

Pequegnat, W., Rosser, B. R. S., Bowen, A. A., Bull, S. S., DiClemente, R. J., Bockting, W. O., Elford, J., Fishbein, M., Gurak, J., Horvath, K., Konstan, J., Noar, S. M., Ross, M. W., Sheer, L., Spiegel, D., \& Zimmerman, R. (2007). Conducting Internet-Based HIV/STD Prevention Survey Research: Considerations in Design and Evaluation. AIDS Behaviour, 11, 505-521.

Peterson, R., Payne, P., Albright, J., Holland, H., Cabral, R. \& Curtis, K.M. (2004). Applying motivational interviewing to contraceptive counselling: ESP for clinicians, Contraception, 69 (3), 213-217.

Phoenix, K. H., \& Coulson, N. S. (2010). Health-Related Internet use by Individuals Living with HIV/AIDS: A Review of the Literature. Health Psychology Update, 19 (2), 12-17.

Polit, D.F. \& Beck, C.T. (2011). Generalization in qualitative and quantitative research: Myths and strategies. International Journal of Nursing Studies, 47 (1 1), 1451-1458.

Prochaska,J.O., \& DiClemente,C.C. (1984). The transtheoretical approach: Crossing traditional boundaries of therapy. Homewood, IL: Dow Jones/Irwin.

Prochaska,J.O., DiClemente,C.C., \& Norcross, J.C. (1992). In search of how people change: Applications to addictive behaviours. American Psychologist, 47, 1102-1114.

Rollnick, S., \& Miller, W. R. (1995). What is Motivational Interviewing? Behavioural and Cognitive Psychotherapy, 23, 325-334.

Sarafino, E.P. (1998). Health Psychology - Biopsychosocial Interactions, (3rd Ed.). New York: John Wiley \& Sons, Inc. 
Shaw, L., \& Cutler, D. (2002) Survey of Clinical Psychologists Working in Sexual Health Settings. London: Faculty of HIV and Sexual Health, Division of Clinical Psychology.

Sheeran, P., Abraham, S. C., Abrams, D., \& Spears, R. (1990). The post AIDS Structure of Students' Attitudes to Condoms: Age, and Sex, and Experience of use. Psychological Reports, $66(2), 614$.

Sheeran, P. \& Taylor, S. (2006). Predicting intentions to use condoms: A meta-analysis and comparison of the theories of reasoned action and planned behaviour. Journal of Applied Social Psychology, 29 (8), 1624-1675.

Sutton, S. (2002). Using social cognition models to develop health behaviour interventions: Problems and assumptions. In D. Rutter \& L. Quine (Ed.), Changing health behaviour (pp.193-208). Maidenhead: Open University Press.

Taylor, J.L. and Lavender, T. (2007). New ways of working for applied psychologists in health and social care - final report of the new roles project group. Leicester: The British Psychological Society.

Weinstein, N. D. (1980). Unrealistic Optimism about Future Life Events. Journal of Personality and Social Psychology, 39 (5), 806-820.

World Health Organisation (2009). AIDS epidemic update. Geneva: UNAIDS.

World Health Organisation (2010). Sexual Health. Retrieved January, 12, 2010, from http://www.who.int/topics/sexual_health/en/

\section{About the authors:}

Jude Hancock is Chartered Psychologist and registered Health Psychologist currently studying for a PhD at Coventry University. Her research is using the Theory of Planned Behaviour to develop an online safer sex intervention, which is applicable to anyone who is currently sexually active or intends to be in the future.

Address for correspondence: Jude Hancock, Applied Research Centre in Health \& Lifestyle Interventions, Faculty of Health \& Life Sciences, Whitefriars Building, Coventry University, Coventry, CV1 5FB.

Email: hancoc16@uni.coventry.ac.uk 
Susan Lees is a trained midwife who is currently a Senior Lecturer in Midwifery at Coventry University. Susan has undertaken research on teenage sexual behaviour and attitudes which included the views of Asian teens on sources of sexual information.

Dr Katherine Brown is a Chartered Psychologist and registered Health Psychologist and is the lead of the SASH (Studies in Adolescent Sexual Health) team at Coventry University (www.healthinterventions.co.uk). Katherine is also the Course Director for the MSc Health Psychology programme in the Universities Psychology Department. 